\title{
Catalytic Allylic Chlorination of Natural Terpenic Olefins Using Supported and Nonsupported Lewis Acid Catalysts
}

\author{
Ayoub Abdelkader Mekkaoui iD, ${ }^{1,2}$ Mouhsine Laayati, ${ }^{1,2}$ Hamza Orfi,, \\ Larbi El Firdoussi $\mathbb{D}^{2}{ }^{2}$ and Soufiane El Houssame $\mathbb{D}^{1}$ \\ ${ }^{1}$ Laboratoire de Chimie, Modélisation et Sciences de l'Environnement, Université Sultan Moulay Slimane, \\ Faculté Polydisciplinaire de Khouribga, BP 145, Khouribga 25000, Morocco \\ ${ }^{2}$ Laboratoire de Chimie de Coordination et de Catalyse, Département de Chimie, Faculté des Sciences Semlalia, BP 2390, \\ Marrakech 40001, Morocco \\ Correspondence should be addressed to Ayoub Abdelkader Mekkaoui; mekk.ayoub@gmail.com and Soufiane El Houssame; \\ hous_soufiane@hotmail.com
}

Received 4 June 2020; Revised 28 July 2020; Accepted 10 August 2020; Published 22 October 2020

Academic Editor: Ioannis D. Kostas

Copyright (c) 2020 Ayoub Abdelkader Mekkaoui et al. This is an open access article distributed under the Creative Commons Attribution License, which permits unrestricted use, distribution, and reproduction in any medium, provided the original work is properly cited.

A mild and convenient method for the allylic chlorination of naturally occurring terpenic olefins was investigated in the presence of different supported and non-supported Lewis acid catalysts. The reaction has been tested on carvone as a model substrate in the presence of sodium hypochlorite as chlorine donor. The scope and limitations of transition metal-based Lewis acid catalysts, stoichiometry, and substrate structure were evaluated. Among the iron precursors used, $\mathrm{FeCl}_{3}$ and $\mathrm{FeCl}_{2}$ provide the promise of a general approach to allylic or vinylic chlorination reaction. Various terpenic olefins were examined in the presence of $\mathrm{FeCl}_{3} /$ $\mathrm{NaOCl}$ combination system. The catalytic chlorination proceeds under mild conditions with short reaction time and shows a high selectivity affording the corresponding chlorides in good to excellent yields.

\section{Introduction}

Allyl, vinyl, or isopropenyl groups are present in different naturally occurring products as part of their structures [1-3]. They have been used repeatedly as starting materials to reach new natural products derivatives or more complex atomic arrangements $[4,5]$. Among the versatile natural products bearing these groups, terpenes represent a sustainable supply of intermediates for several functionalization segments of the fine chemical industry, for example, the manufacture of flavors and fragrances [6-8]. Allylic chlorination represents a convenient way to functionalize terpenes bearing an allyl, vinyl, or isopropenyl group since further manipulation on the chloride may lead to several functional groups for the synthesis of natural products [9-13]. Previously, we have reported the allylic substitution of optically active natural terpenic allylic chloride derivatives in good yields [14, 15]. Moreover, isoprenoid chlorides are remarkably interesting for the synthesis of $\alpha$-monoterpenes or vitamin A intermediates such as pseudoionone [16-18].

Allylic chlorination represents a convenient alternative method for allylic olefins functionalization. Various methodologies developing the allylic chlorination are reported in the literature, allowing the preparation of allyl chloride derivatives from the corresponding allylic alcohols using different reagents, such as thionyl chloride [19], hydrochloric acid [20], titanium (IV) chloride [21], N-chlorosuccinimide (NCS) [22], chlorosilanes [23, 24], methanesulfonyl chloride/lithium chloride [25], or iridium catalyst [26, 27]. Moreover, allylic chloride intermediates could be synthesized from aldehydes through olefinationreduction-halogenation sequences [28]. Torii et al. have reported electrochemical methods using sodium chloride as halogen source for the allylic chlorination of variety of isoprenoids $[29,30]$. In organic synthesis, diselenides were also used as catalysts for the allylic chlorination of olefins 


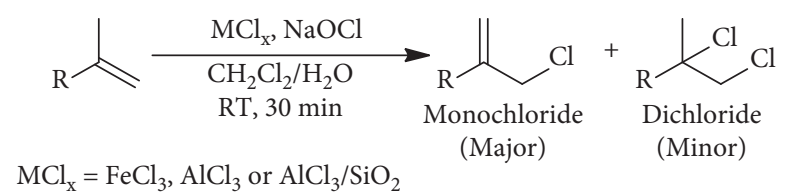

Scheme 1: Allylic chlorination of terminal olefins catalyzed by $\mathrm{MCl}_{\mathrm{x}}$.

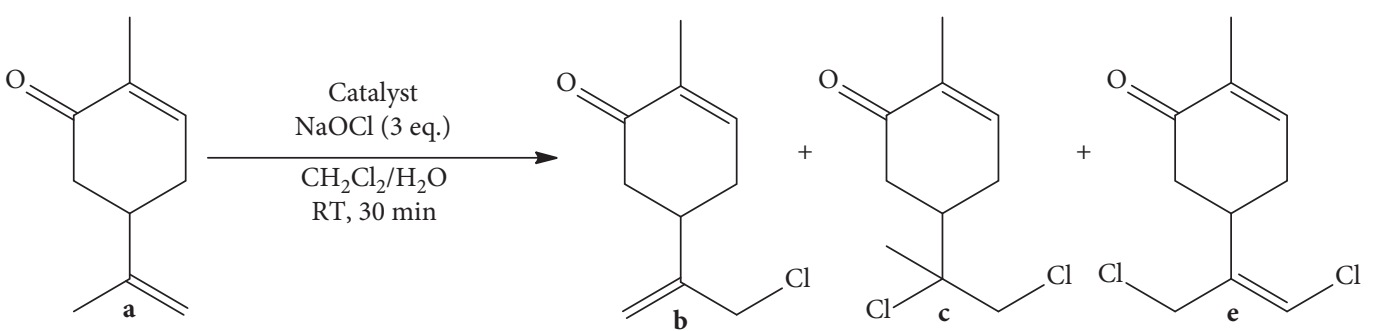

Scheme 2: Allylic chlorination of carvone.

TABLE 1: Allylic chlorination of carvone using different Lewis acid catalysts.

\begin{tabular}{|c|c|c|c|c|c|c|}
\hline \multirow{2}{*}{ Entry } & \multirow{2}{*}{ Catalyst } & \multirow{2}{*}{ Catalyst/substrate* } & \multirow{2}{*}{$\begin{array}{c}\text { Conversion } \\
\text { a }(\%)\end{array}$} & \multicolumn{3}{|c|}{ Selectivity } \\
\hline & & & & $\mathrm{b}(\%)$ & c (\%) & e $(\%)$ \\
\hline 1 & $\mathrm{AlCl}_{3} / \mathrm{SiO}_{2} 10 \%$ wt $\%$ & $40 \%$ wt./wt. & 25 & 6 & 4,7 & 0 \\
\hline 2 & $\mathrm{AlCl}_{3} / \mathrm{SiO}_{2} 10 \% \mathrm{wt} \%$ & 3 eq. of $\mathrm{AlCl}_{3}$ & 74 & 53 & 20 & 0 \\
\hline 3 & $\mathrm{AlCl}_{3}$ & 3 & 74 & 60 & 14 & 0 \\
\hline 4 & $\mathrm{FeCl}_{3}$ & 3 & 84 & 68 & 6 & 0 \\
\hline 5 & $\mathrm{FeCl}_{2}$ & 3 & 99 & 4 & 12 & 84 \\
\hline 6 & $\mathrm{Fe}\left(\mathrm{NO}_{3}\right)_{3}$ & 3 & 99 & 33 & 15 & 52 \\
\hline 7 & $\mathrm{Fe}(\mathrm{acac})_{3}$ & 3 & 0 & 0 & 0 & 0 \\
\hline 8 & $\mathrm{MoCl}_{5}$ & 3 & 99 & 75 & 10 & 14 \\
\hline
\end{tabular}

*Reaction conditions: $\mathrm{NaOCl}$ ( 3 eq.), $\mathrm{CH}_{2} \mathrm{Cl}_{2} / \mathrm{H}_{2} \mathrm{O}(1: 1,10 \mathrm{~mL})$, RT, and $30 \mathrm{~min}$.

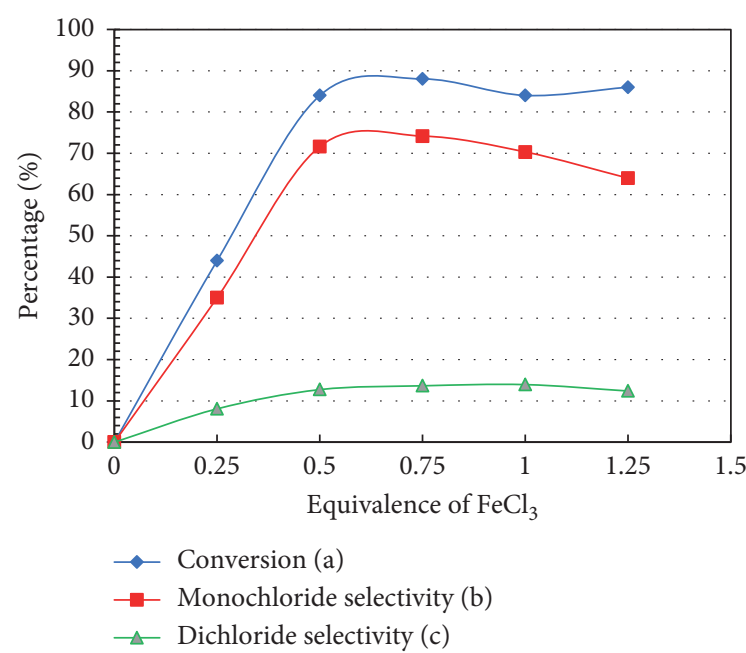

Figure 1: Effect of $\mathrm{FeCl}_{3}$ amount.

[31-33]. Barrero et al. have reported a solid-phase selenium catalyst for the selective allylic chlorination of polyprenoids [34]. Recently, we have prepared an efficient new organoselenide for the allylic chlorination of various terpenic olefins [35]. In the presence of NCS, the allylic chloride can

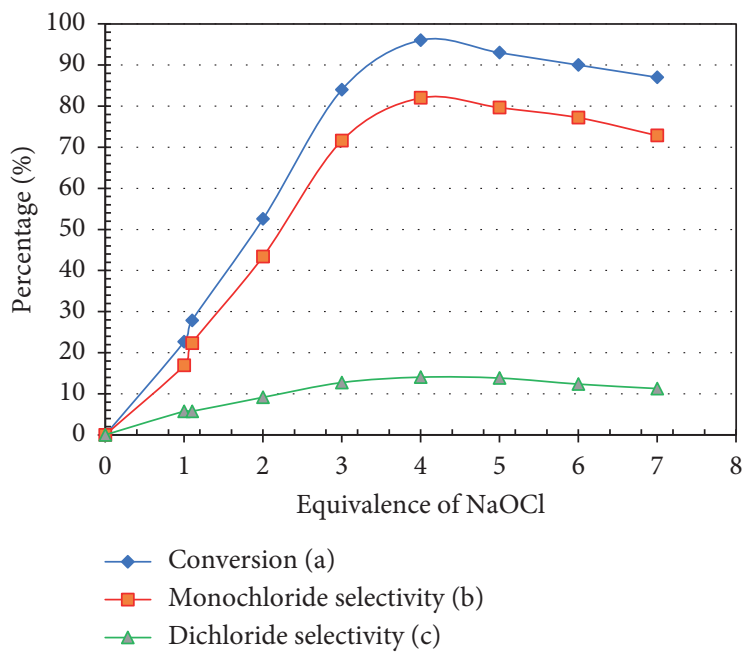

Figure 2: Effect of $\mathrm{NaOCl}$ amount.

be prepared from olefins using $\mathrm{Yb}(\mathrm{OTf})_{3}-\mathrm{TMSCl}$ or aniline catalyst [36, 37], while the allylic chlorination could be performed by a direct molecular chlorine bubbling through the reaction medium but suffer from disadvantages such as difficulties of handling chlorine gas [38]. On the other hand, reports are focused on the use of calcium hypochlorite 
TABLE 2: Allylic chlorination of nonfunctionalized terpenic olefins ${ }^{\mathrm{a}}$. Entry Substrate Conversion $^{\mathrm{b}}(\%) \quad$ Product/isolated yield (\%)
1<smiles>CC1=CCC2CC1C2(C)C</smiles>

99
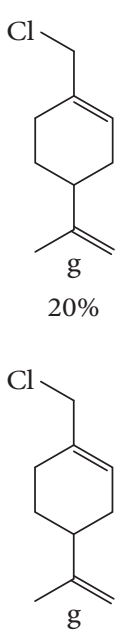

$10 \%$

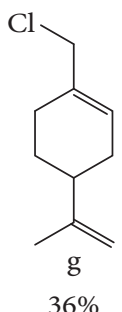

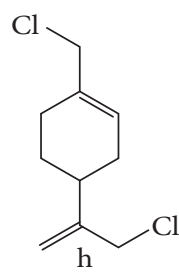

$18 \%$

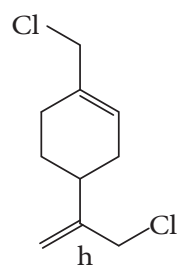

$41 \%$

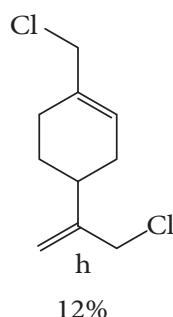

${ }^{a}$ Reaction conditions: $\mathrm{FeCl}_{3}$ (0.5 eq.), $\mathrm{NaOCl}$ (4 eq.), $\mathrm{CH}_{2} \mathrm{Cl}_{2} / \mathrm{H}_{2} \mathrm{O}$ (1:1, $10 \mathrm{~mL}$ ), RT, and $30 \mathrm{~min}$. ${ }^{\mathrm{b}}$ Conversion was determined by $\mathrm{GC}$ using dodecane as an internal standard.

$[39,40]$ or by a combination of Vilsmeier reagent and $\mathrm{H}_{2} \mathrm{O}_{2}$, but this excludes the use of acid-sensitive substrates [41]. In addition, sodium hypochlorite and acetic acid were used for the chlorine generation with limitation to nonsensitive substrates [42].

In the last two decades, the use of Brønsted acid (acetic acid) instead of Lewis acid has gained considerable importance. The method has the advantage of mild reaction conditions when the reaction occurs in a smoothly twophase system $\left(\mathrm{CH}_{2} \mathrm{Cl}_{2} / \mathrm{H}_{2} \mathrm{O}\right)$ [38]. Different metallic Lewis acids in combination with $\mathrm{NaOCl}$ were studied for the allylic chlorination of terpenic olefins such as $\mathrm{CeCl}_{3}, \mathrm{InCl}_{3}$, or $\mathrm{MoCl}_{5}[38,43,44]$. The optimum solvent was reported to be the biphasic system of dichloromethane and water with addition of sodium hypochlorite under vigorous stirring to ensure the homogeneous distribution of the in situ generated electrophilic chlorine [38]. Moreover, Lewis acids such as $\mathrm{NbCl}_{5}$ and $\mathrm{NbBr}_{5}$ are reported to be efficient for the allylic and allenic chlorination via a mediated alkoxide rearrangements [28].

As part of our studies directed towards the valorization of natural terpenes via new catalytic systems [45-47], herein we report an efficient and convenient method for the allylic chlorination of terpenes using a combination of sodium hypochlorite and Lewis acid catalyst. The allylic chlorination was achieved in a high degree of efficiency and selectivity. Among the Lewis acids used, aluminum and iron salts exhibit multiple interesting features such as their high abundance, low environmental impact, high chemoselectivity, and tolerance to aqueous media. The method represents a good choice for the preparation of new functionalized compounds derived from natural products under mild conditions (Scheme 1).

\section{Results and Discussion}

The scope and limitation of the allylic chlorination was examined first using carvone, chosen as model substrate, in the presence of supported and nonsupported Lewis acid catalysts (Scheme 2). The results are summarized in Table 1.

First, we have checked the reaction in the presence of a prepared supported catalyst $\mathrm{AlCl}_{3} / \mathrm{SiO}_{2} 10 \%$ wt $\%$ (Table 1, entries 1-2). A slight conversion is observed when the reaction is carried out with a catalytic amount of a prepared supported catalyst $\mathrm{AlCl}_{3} / \mathrm{SiO}_{2} 10 \%$ wt $\%$ (entry 1 ). However, a conversion of $74 \%$ with selectivity of $53 \%$ (b) and $10 \%$ (c) were obtained with a stoichiometric amount of $\mathrm{AlCl}_{3} / \mathrm{SiO}_{2}$ $10 \% \mathrm{wt} \%$ (entry 2). From entries 1 and 2, we can assume that supported catalyst is less efficient for the allylic chlorination of terminal olefins due to the need of a stoichiometric amount of the Lewis acid.

The use of nonsupported catalyst $\mathrm{AlCl}_{3}$ leads to similar result (entry 3). Table 1 shows that $\mathrm{FeCl}_{3}$ was the most reactive and selective catalyst towards monochloride (b) (entry 4). The catalytic activity of different iron Lewis acid catalysts has been performed (entries 4-7). While the presence of $\mathrm{FeCl}_{3}$ orients the reaction towards the formation of the allylic monochloride (b), $\mathrm{FeCl}_{2}$ gave mainly the vinyl allyl dichloride (e) with $86 \%$ of yield (entry 5 ). The examination of iron(III) Lewis catalyst ligands effect indicates that with acetylacetone practically no reaction took place which could be due to the ligand steric hindrance effect (entry 7). When the reaction was carried out with $\mathrm{MoCl}_{5}$, the corresponding monochloride (b) is formed as the major product (entry 8). It appeared that the molybdenum catalyst promotes the formation of allylic monochloride (b) with a moderate selectivity of dichloride (c) and vinyl allyl dichloride (e) contrarily to what was reported previously [44].

The catalytic chlorination of carvone (a) was performed by varying the amount of $\mathrm{FeCl}_{3}$ (Figure 1). In the absence of Lewis acid catalyst, no reaction was observed even after stirring for a long reaction time. The increase of the $\mathrm{FeCl}_{3}$ equivalence resulted in the increase of the conversion of carvone (a) with the formation of both the mono- and dichloride product. The best result was obtained with 0.5 equivalence of catalyst, and a conversion of $84 \%$ was obtained. The 0.75 equivalence amount reached a slight increase of conversion with no significant increase of selectivity.

The effect of $\mathrm{NaOCl}$ on the allylic chlorination reaction was evaluated using 0.5 eq. of $\mathrm{FeCl}_{3}$ (Figure 2). In the absence of $\mathrm{NaOCl}$ as a chlorination agent, no reaction took place even in presence of Lewis acid catalyst. An excess of 
TABLE 3: Allylic chlorination of functionalized terpenes ${ }^{\mathrm{a}}$.

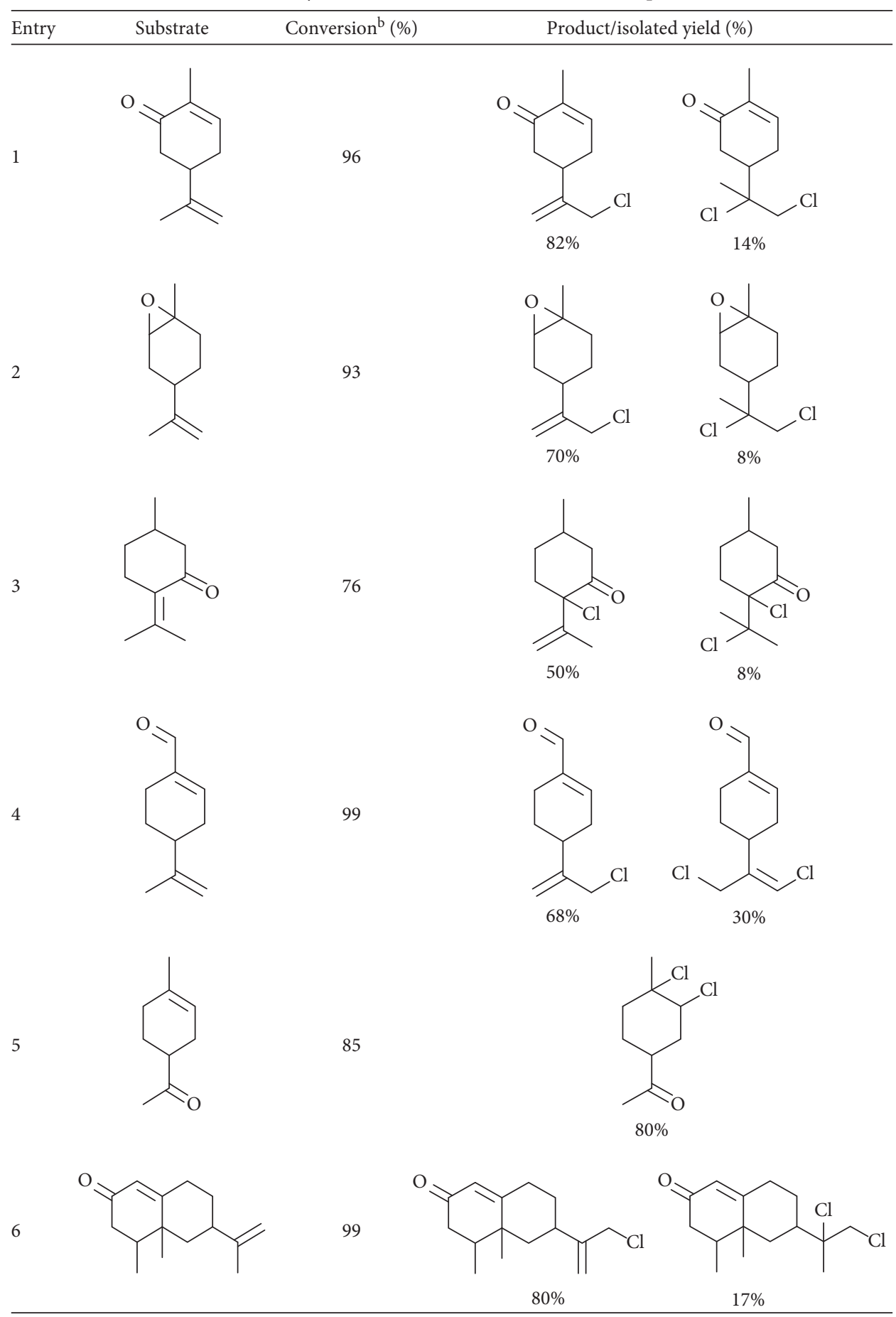

${ }^{\mathrm{a}}$ Reaction conditions: $\mathrm{FeCl}_{3}$ (0.5 eq.), $\mathrm{NaOCl}$ (4 eq.), $\mathrm{CH}_{2} \mathrm{Cl}_{2} / \mathrm{H}_{2} \mathrm{O}(1: 1,10 \mathrm{~mL})$, RT, and 30 min. ${ }^{\mathrm{b}}$ Conversion was determined by GC using dodecane as an internal standard.

$\mathrm{NaOCl}$ up to 4 equivalence resulted in a maximum of conversion (96\%) and a maximum of selectivity of (b) (82\%).

According to the literature $[38,43,44]$, the modest selectivity of dichlorinated product proved its presence for the first time in Lewis acid catalytic system. In order to confirm the formation of dichloride compound, a chlorination reaction starting from monochloride (b) was carried out and no conversion was observed. Based on this result, we can predict that the dichlorinated product is formed by direct addition on the double bond.

Under the optimized conditions with $\mathrm{FeCl}_{3}$ as a catalyst, allylic chlorination of various nonfunctionalized olefins has been carried out (Table 2 ). All the proposed terpenic olefins ( $\alpha$-pinene $\mathrm{d}, \beta$-pinene e, and limonene f) were converted 


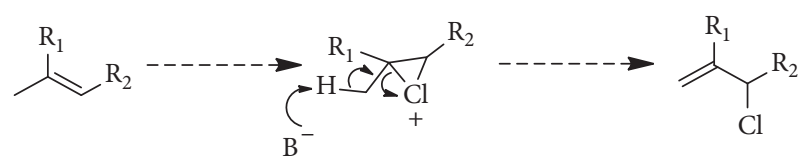

Scheme 3: Proposed mechanism of allylic chlorination of terpenic olefins.

totally to the corresponding monochlorinated $\mathrm{g}$ and the dichlorinated h. At lower temperature of $0^{\circ} \mathrm{C}$, no improvement on the selectivity is detected. In addition, a complex mixture was obtained.

To shed more light on the activity of $\mathrm{FeCl}_{3}$, we have extended the allylic chlorination to a much more demanding functionalized terpenic olefins such as limonene oxide, pulegone, perillyl aldehyde, limona ketone and nootkatone (Table 3). The results depicted in Table 3 demonstrate that functionalized terpenic olefins were found to be more reactive than the nonfunctionalized ones. Except for limona ketone (entry 5), all substrates were converted to the corresponding allylic monochlorides as a major product (entries 1-4 and 6). It is noteworthy that perillyl aldehyde and carvone lead to the formation of a new vinyl allyl dichlorides in moderate yield (entries 5-6 (Table 1) and entry 4 (Table 3)). As vinyl chloride derivatives represent great interest in organic synthesis and biological activity [38, 48, 49], this procedure may serve as a tool for their synthesis in a simple one step. All isolated pure products were fully characterized by ${ }^{1} \mathrm{H},{ }^{13} \mathrm{C} \mathrm{NMR}$, and mass spectroscopy (Supporting Information, Figures S1-S41).

Despite no reaction took place in the absence of Lewis acid catalyst, it has been reported that chlorine is usually generated from $\mathrm{NaOCl}[38,43,44]$. The allylic chlorination reaction is probably based on the mild generation of electrophilic chlorine from $\mathrm{NaOCl}$ to a chlorination of the corresponding alkene. The loss of proton of the cationic intermediate leads to the formation of the major allylic chlorinated product (Scheme 3).

\section{Conclusion}

An efficient methodology for the catalytic allylic chlorination of naturally occurring terpenes using inexpensive and readily available Lewis acid catalysts combined with $\mathrm{NaOCl}$ has been investigated. The reaction was performed with a high degree of efficiency and selectivity. All the proposed terpenic olefins exhibit marked activity under mild conditions and lead to the corresponding mono- or dichlorides derivatives in good yields. Various supported and nonsupported Lewis acid catalysts were studied. Different iron precursors have been checked and interesting results have been obtained with $\mathrm{FeCl}_{3}$ and $\mathrm{FeCl}_{2}$. The reaction provides a useful entry to new functionalized terpenic olefin products.

\section{General Procedure}

In a typical procedure, terpenic olefin $(1 \mathrm{mmol})$ in $10 \mathrm{~mL}$ of $\mathrm{CH}_{2} \mathrm{Cl}_{2}$ is added to a vigorously stirred solution of $\mathrm{FeCl}_{3}(0.5$ eq.) in $10 \mathrm{~mL}$ of $\mathrm{H}_{2} \mathrm{O}$. The mixture is vigorously stirred and a diluted $\mathrm{NaOCl}$ (4 eq.) is added dropwise for $5 \mathrm{~min}$. After
30 min, a saturated aqueous $\mathrm{Na}_{2} \mathrm{SO}_{3}$ solution is added and the mixture is extracted with $\mathrm{CH}_{2} \mathrm{Cl}_{2}(3 \times 10 \mathrm{~mL})$. The organic layer is dried over anhydrous $\mathrm{Na}_{2} \mathrm{SO}_{4}$. Then, the solvent was removed under reduced pressure. The pure chlorinated products were obtained by column chromatography over silica gel using hexane and ethyl acetate as eluents. The isolated pure products were fully characterized by ${ }^{1} \mathrm{H},{ }^{13} \mathrm{C} \mathrm{NMR}$, and GC-MS.

Carvone monochloride $\mathrm{b}$

1H NMR (300 MHz) d $6.69(\mathrm{~m}, 1 \mathrm{H},=\mathrm{CH}), 5.19(\mathrm{~s}, 1 \mathrm{H}$, $\left.=\mathrm{CH}_{2}\right), 4.99\left(\mathrm{~s}, 1 \mathrm{H},=\mathrm{CH}_{2}\right), 4.03\left(\mathrm{~s}, 2 \mathrm{H},-\mathrm{CH}_{2} \mathrm{Cl}\right), 2.9$ (m, 1H, CH), $2.61\left(\mathrm{~m}, 2 \mathrm{H}, \mathrm{CH}_{2}\right), 2.4\left(\mathrm{~m}, 2 \mathrm{H}, \mathrm{CH}_{2}\right)$, $1.75\left(\mathrm{~s}, 3 \mathrm{H},-\mathrm{CH}_{3}\right)$. 13C NMR $(75 \mathrm{MHz})$ d 198.8 $(\mathrm{C}=\mathrm{O}), 146.5$ (=C-), 144.1 (=CH-), 135.5 (=C-), $115.0\left(=\mathrm{CH}_{2}\right), 46.9\left(\mathrm{CH}_{2} \mathrm{Cl}\right), 43.0\left(\mathrm{CH}_{2}\right), 37.8(\mathrm{CH})$, $31.3\left(\mathrm{CH}_{2}\right), 15.6\left(\mathrm{CH}_{3}\right)$. MS (EI): $\mathrm{m} / \mathrm{z}=184.0176[\mathrm{M}]^{+}$.

Carvone dichloride $\mathbf{c}$

$1 \mathrm{H} \mathrm{NMR}(300 \mathrm{MHz})$ d $7.21(\mathrm{~m}, 1 \mathrm{H},=\mathrm{CH}), 3.45(\mathrm{~m}$, $\left.2 \mathrm{H},-\mathrm{CH}_{2} \mathrm{Cl}\right), 2.5\left(\mathrm{~m}, 2 \mathrm{H}, \mathrm{CH}_{2}\right), 2.3(\mathrm{~m}, 1 \mathrm{H}, \mathrm{CH}), 2.15$ (m, 2H, $\left.\mathrm{CH}_{2}\right), 1.71\left(\mathrm{~s}, 3 \mathrm{H},-\mathrm{CH}_{3}\right), 1.19\left(\mathrm{~s}, 3 \mathrm{H},-\mathrm{CH}_{3}\right)$. 13C NMR (75 MHz) d $198.0(\mathrm{C}=\mathrm{O}), 144.15$ (=CH-), 135.30 (=C-), $72.69(-\mathrm{C}-\mathrm{Cl}), 52.60\left(\mathrm{CH}_{2} \mathrm{Cl}\right), 41.64$ $(\mathrm{CH}), 39.36\left(\mathrm{CH}_{2}\right), 26.28\left(\mathrm{CH}_{2}\right), 21.80\left(\mathrm{CH}_{3}\right), 15.62$ $\left(\mathrm{CH}_{3}\right)$. MS (EI): $\mathrm{m} / \mathrm{z}=220.0758[\mathrm{M}]^{+}$.

Carvone vinyl allyl dichloride e

1H NMR (300 MHz) d $6.74(\mathrm{~m}, 1 \mathrm{H},=\mathrm{CH}), 6.12(\mathrm{~s}, 1 \mathrm{H}$, $=\mathrm{CHCl}), 4.20\left(\mathrm{~s}, 2 \mathrm{H},-\mathrm{CH}_{2} \mathrm{Cl}\right), 3.00(\mathrm{~m}, 1 \mathrm{H}, \mathrm{CH}), 2.60$ (m, 2H, $\left.\mathrm{CH}_{2}\right), 2.49\left(\mathrm{~m}, 2 \mathrm{H}, \mathrm{CH}_{2}\right), 1.70\left(\mathrm{~s}, 3 \mathrm{H},-\mathrm{CH}_{3}\right)$. 13C NMR (75 MHz) d 197.97 (C=O), 143.69 (=CH-), 139.70 (=C-), 135.77 (=C-), 119.91 (=CHCl), 42.40 $\left(-\mathrm{CH}_{2} \mathrm{Cl}\right), 42.0\left(\mathrm{CH}_{2}\right), 39.56(\mathrm{CH}), 31.15\left(\mathrm{CH}_{2}\right), 15.62$ $\left(\mathrm{CH}_{3}\right)$. MS (EI): $\mathrm{m} / \mathrm{z}=218[\mathrm{M}]^{+}$.

Limonene oxide monochloride

$1 \mathrm{H} \mathrm{NMR}(300 \mathrm{MHz}) \mathrm{d} 4.96\left(\mathrm{~s}, 1 \mathrm{H},=\mathrm{CH}_{2}\right), 4.95(\mathrm{~s}, 1 \mathrm{H}$, $\left.=\mathrm{CH}_{2}\right), 4.02\left(\mathrm{~s}, 2 \mathrm{H},-\mathrm{CH}_{2} \mathrm{Cl}\right), 2.99(\mathrm{~m}, 1 \mathrm{H},-\mathrm{O}-\mathrm{CH}-)$, $2.36(\mathrm{~m}, 1 \mathrm{H}, \mathrm{CH}), 1.35-1.93(\mathrm{~m}, 6 \mathrm{H}), 1.30(\mathrm{~s}, 3 \mathrm{H}$, $\left.-\mathrm{CH}_{3}\right) .13 \mathrm{C} \mathrm{NMR}(75 \mathrm{MHz})$ d 148.76 (=C-), 113.65 $\left(=\mathrm{CH}_{2}\right), 58.97(\mathrm{O}-\mathrm{CH}), 57.12(\mathrm{O}-\mathrm{C}), 47.37\left(\mathrm{CH}_{2} \mathrm{Cl}\right)$, $32.42(\mathrm{CH}), 30.70\left(\mathrm{CH}_{2}\right), 28.46\left(\mathrm{CH}_{2}\right), 24.66\left(\mathrm{CH}_{2}\right)$, $22.96\left(\mathrm{CH}_{3}\right)$. MS (EI): $\mathrm{m} / \mathrm{z}=185.0668[\mathrm{M}]^{+}$.

Limonene oxide dichloride

1H NMR (300 MHz) d 3.55 (s, 2H,- $\left.\mathrm{CH}_{2} \mathrm{Cl}\right), 3.02$ (m, $1 \mathrm{H},-\mathrm{O}-\mathrm{CH}-), 2.05$ (m, 1H, CH), 2.01-1.50 (m, 6H), $1.33\left(\mathrm{~s}, 3 \mathrm{H},-\mathrm{CH}_{3}\right), 1.13\left(\mathrm{~s}, 3 \mathrm{H},-\mathrm{CH}_{3}\right) .13 \mathrm{C} \mathrm{NMR}$ $(75 \mathrm{MHz})$ d 73.37 (-C-Cl), $58.78(\mathrm{O}-\mathrm{CH}), 57.66$ (O-C), $53.23\left(\mathrm{CH}_{2} \mathrm{Cl}\right), 39.78(\mathrm{CH}), 30.58\left(\mathrm{CH}_{2}\right), 24.89$ $\left(\mathrm{CH}_{2}\right), 22.85\left(\mathrm{CH}_{3}\right), 22.96\left(\mathrm{CH}_{3}\right), 20.45\left(\mathrm{CH}_{2}\right) . \mathrm{MS}$ (EI): $\mathrm{m} / \mathrm{z}=220.9909[\mathrm{M}]^{+}$.

Pulegone monochloride

$1 \mathrm{H}$ NMR $(300 \mathrm{MHz}) \mathrm{d} 5.20\left(\mathrm{~s}, 1 \mathrm{H},=\mathrm{CH}_{2}\right), 5.14(\mathrm{~s}, 1 \mathrm{H}$, $\left.=\mathrm{CH}_{2}\right), 2.35-2.80\left(\mathrm{~m}, 2 \mathrm{H}, \mathrm{CH}_{2}\right), 2.30\left(\mathrm{~m}, 2 \mathrm{H}, \mathrm{CH}_{2}\right)$, $1.96(\mathrm{~m}, 1 \mathrm{H}, \mathrm{CH}), 1.90\left(\mathrm{~m}, 3 \mathrm{H},-\mathrm{CH}_{3}\right), 1.84(\mathrm{~m}$, $\left.2 \mathrm{H}, \mathrm{CH}_{2}\right), \quad 1.06 \quad\left(\mathrm{~d}, \quad 3 \mathrm{H}, \quad-\mathrm{CH}_{3}\right) . \quad 13 \mathrm{C} \quad \mathrm{NMR}$ 
$(75 \mathrm{MHz})$ d 203.76 (C=O), 143.44 (=C-), 115.25 $\left(=\mathrm{CH}_{2}\right), 76.09(-\mathrm{C}-\mathrm{Cl}), 45.54\left(\mathrm{CH}_{2}\right), 37.97\left(\mathrm{CH}_{2}\right)$, $34.39(\mathrm{CH}), 29.64\left(\mathrm{CH}_{2}\right), 21.48\left(\mathrm{CH}_{3}\right), 20.58\left(\mathrm{CH}_{3}\right)$. MS (EI): $\mathrm{m} / \mathrm{z}=186.1188[\mathrm{M}]^{+}$.

Pulegone dichloride

$1 \mathrm{H}$ NMR $(300 \mathrm{MHz})$ d 2.38-2.86 (m, 2H, $\left.\mathrm{CH}_{2}\right), 2.15$ (m, 1H, CH), 1.79-2.38 (m, 2H, $\left.\mathrm{CH}_{2}\right), 1.79(\mathrm{~m}, 2 \mathrm{H}$, $\mathrm{CH}_{2}$ ), 1.44 (s, 3H, $-\mathrm{CH}_{3}$ ), 1.35 (s, 3H, $\left.-\mathrm{CH}_{3}\right), 1.05$ (d, $\left.3 \mathrm{H},-\mathrm{CH}_{3}\right) .13 \mathrm{C} \mathrm{NMR}(75 \mathrm{MHz})$ d $208.21(\mathrm{C}=\mathrm{O})$, $75.13(-\mathrm{C}-\mathrm{Cl}), 74.96(-\mathrm{C}-\mathrm{Cl}), 46.63\left(\mathrm{CH}_{2}\right), 35.22$ $\left(\mathrm{CH}_{2}\right), 29.49\left(\mathrm{CH}_{2}\right), 25.52(\mathrm{CH}), 21.99\left(2 \mathrm{CH}_{3}\right), 18.15$ $\left(\mathrm{CH}_{3}\right)$. MS (EI): $\mathrm{m} / \mathrm{z}=222.9984[\mathrm{M}]^{+}$.

Perillyl aldehyde monochloride

1H NMR (300 MHz) d 9.43 (s, 1H, HC=O), $6.83(\mathrm{~m}$, $1 \mathrm{H},=\mathrm{CH}), 5.23\left(\mathrm{~s}, 1 \mathrm{H},=\mathrm{CH}_{2}\right), 5.02\left(\mathrm{~s}, 1 \mathrm{H},=\mathrm{CH}_{2}\right)$, 4.09 (s, $\left.2 \mathrm{H},-\mathrm{CH}_{2} \mathrm{Cl}\right), 2.02-2.53\left(\mathrm{~m}, 2 \mathrm{H}, \mathrm{CH}_{2}\right), 2.25(\mathrm{~m}$, $1 \mathrm{H}, \mathrm{CH}), 1.42-1.72\left(\mathrm{~m}, 2 \mathrm{H}, \mathrm{CH}_{2}\right), 0.87-1.24(\mathrm{~m}, 2 \mathrm{H}$, $\left.-\mathrm{CH}_{2}\right) .13 \mathrm{C}$ NMR $(75 \mathrm{MHz})$ d $193.74(\mathrm{HC}=\mathrm{O}), 149.82$ (=CH-), 148.25 (=C-), 141.15 (=C-), $114.20\left(=\mathrm{CH}_{2}\right)$, $47.56\left(\mathrm{CH}_{2} \mathrm{Cl}\right), 36.21(\mathrm{CH}), 32.13\left(\mathrm{CH}_{2}\right), 26.51\left(\mathrm{CH}_{2}\right)$, $21.46\left(\mathrm{CH}_{2}\right)$. MS (EI): $\mathrm{m} / \mathrm{z}=184.0441[\mathrm{M}]^{+}$.

Perillyl aldehyde vinyl allyl dichloride

1H NMR (300 MHz) d $9.45(\mathrm{~s}, 1 \mathrm{H}, \mathrm{HC}=\mathrm{O}), 6.82(\mathrm{~m}$, $1 \mathrm{H},=\mathrm{CH}), 6.12(\mathrm{~m}, 1 \mathrm{H},=\mathrm{CHCl}), 4.29\left(\mathrm{~s}, 2 \mathrm{H},-\mathrm{CH}_{2} \mathrm{Cl}\right)$, 1.58-2.59 (m, 2H, $\left.\mathrm{CH}_{2}\right), 1.99(\mathrm{~m}, 1 \mathrm{H}, \mathrm{CH}), 1.26(\mathrm{~m}$, $\left.2 \mathrm{H},-\mathrm{CH}_{2}\right), 0.87-2.30\left(\mathrm{~m}, 2 \mathrm{H}, \mathrm{CH}_{2}\right) .13 \mathrm{C} \mathrm{NMR}$ (75 MHz) d $193.51(\mathrm{HC}=\mathrm{O}), 148.79$ (=CH-), 141.26 (=C-), 141.10 (=C-), 119.00 (=CHCl), $40.11\left(\mathrm{CH}_{2} \mathrm{Cl}\right)$, $37.86(\mathrm{CH}), 31.81\left(\mathrm{CH}_{2}\right), 26.28\left(\mathrm{CH}_{2}\right), 21.40\left(\mathrm{CH}_{2}\right)$. MS (EI): $\mathrm{m} / \mathrm{z}=218.0015[\mathrm{M}]^{+}$.

Limona ketone dichloride

$1 \mathrm{H}$ NMR (300 MHz) d $4.04(\mathrm{~m}, 1 \mathrm{H},-\mathrm{CHCl}), 2.82$ (m, $1 \mathrm{H}, \mathrm{CH}), 1.89-2.35\left(\mathrm{~m}, 2 \mathrm{H}, \mathrm{CH}_{2}\right), 2.17\left(\mathrm{~s}, 3 \mathrm{H},-\mathrm{CH}_{3}\right)$, 1.76-1.95 (m, 2H, $\left.\mathrm{CH}_{2}\right), 1.56-1.76\left(\mathrm{~m}, 2 \mathrm{H}, \mathrm{CH}_{2}\right), 1.35$ $\left(\mathrm{s}, 3 \mathrm{H},-\mathrm{CH}_{3}\right) .13 \mathrm{C} \mathrm{NMR}(75 \mathrm{MHz}) \mathrm{d} 211.13(\mathrm{C}=\mathrm{O})$, 71.46 (-CCl), 64.75 (-CHCl), $44.64(\mathrm{CH}), 32.62$ $\left(\mathrm{CH}_{2}\right), 31.80\left(\mathrm{CH}_{2}\right), 28.14\left(\mathrm{CH}_{3}\right), 27.32\left(\mathrm{CH}_{3}\right), 23.28$ $\left(\mathrm{CH}_{2}\right)$. MS (EI): $\mathrm{m} / \mathrm{z}=206.9165[\mathrm{M}]^{+}$.

Nootkatone monochloride

$1 \mathrm{H}$ NMR $(300 \mathrm{MHz})$ d $5.66(\mathrm{~m}, 1 \mathrm{H},=\mathrm{CH}), 5.09(\mathrm{~s}, 1 \mathrm{H}$, $\left.=\mathrm{CH}_{2}\right), 4.90\left(\mathrm{~s}, 1 \mathrm{H},=\mathrm{CH}_{2}\right), 4.01\left(\mathrm{~s}, 2 \mathrm{H},-\mathrm{CH}_{2} \mathrm{Cl}\right), 2.47$ (m, 2H, $\mathrm{CH}_{2}$ ), $2.29(\mathrm{~m}, 1 \mathrm{H}, \mathrm{CH}), 2.15\left(\mathrm{~m}, 2 \mathrm{H}, \mathrm{CH}_{2}\right.$ ), $1.91\left(\mathrm{~m}, 2 \mathrm{H}, \mathrm{CH}_{2}\right), 1.27(\mathrm{~m}, 1 \mathrm{H}, \mathrm{CH}), 1.04-1.97(\mathrm{~m}$, $\left.2 \mathrm{H}, \mathrm{CH}_{2}\right), 1.04\left(\mathrm{~s}, 3 \mathrm{H},-\mathrm{CH}_{3}\right), 0.87\left(\mathrm{~d}, 3 \mathrm{H},-\mathrm{CH}_{3}\right) .13 \mathrm{C}$ NMR (75 MHz) d 199.08 (C=O), 169.58 (=C-), 148.67 $(=\mathrm{C}-), \quad 124.74 \quad(=\mathrm{CH}-), \quad 113.80 \quad\left(=\mathrm{CH}_{2}\right), \quad 47.70$ (CH2Cl), $44.17\left(\mathrm{CH}_{2}\right), 41.95\left(\mathrm{CH}_{2}\right), 40.30(\mathrm{CH}), 39.35$ (-C-), $35.72(\mathrm{CH}), 32.85\left(\mathrm{CH}_{2}\right), 31.91\left(\mathrm{CH}_{2}\right), 16.67$ $\left(\mathrm{CH}_{3}\right), 14.87\left(\mathrm{CH}_{3}\right)$. MS (EI): $\mathrm{m} / \mathrm{z}=252.0591[\mathrm{M}]^{+}$.

Nootkatone dichloride

1H NMR (300 MHz) d $5.76(\mathrm{~m}, 1 \mathrm{H},=\mathrm{CH}), 3.57(\mathrm{~m}$, $\left.1 \mathrm{H}, \mathrm{CH}_{2} \mathrm{Cl}\right), 3.64\left(\mathrm{~m}, 1 \mathrm{H}, \mathrm{CH}_{2} \mathrm{Cl}\right), 2.40(\mathrm{~m}, 1 \mathrm{H}, \mathrm{CH})$, 2.23-2.50 (m, 2H, $\left.\mathrm{CH}_{2}\right), 2.06\left(\mathrm{~m}, 2 \mathrm{H}, \mathrm{CH}_{2}\right), 1.99-2.29$ (m, 2H, $\left.\mathrm{CH}_{2}\right), 1.87-2.12\left(\mathrm{~m}, 2 \mathrm{H}, \mathrm{CH}_{2}\right), 1.25(\mathrm{~m}, 1 \mathrm{H}$, $\mathrm{CH}), 1.19\left(\mathrm{~s}, 3 \mathrm{H},-\mathrm{CH}_{3}\right), 1.10\left(\mathrm{~m}, 3 \mathrm{H},-\mathrm{CH}_{3}\right), 0.98(\mathrm{~m}$, $\left.3 \mathrm{H},-\mathrm{CH}_{3}\right) .13 \mathrm{C} \mathrm{NMR}(75 \mathrm{MHz})$ d 199.50 (C=O), 170.08 (=C-), 124.62 (=CH-), 73.33 (-CCl), 53.47 $\left(\mathrm{CH}_{2} \mathrm{Cl}\right), 42.04\left(\mathrm{CH}_{2}\right), 40.53(\mathrm{CH}), 39.96(\mathrm{CH}), 39.68$ $(\mathrm{CH}), 32.72\left(\mathrm{CH}_{2}\right), 27.70\left(\mathrm{CH}_{2}\right), 26.67\left(\mathrm{CH}_{2}\right), 21.22$ $\left(\mathrm{CH}_{3}\right), 16.75\left(\mathrm{CH}_{3}\right), 14.96\left(\mathrm{CH}_{3}\right) . \mathrm{MS}(\mathrm{EI}): \mathrm{m} /$ $\mathrm{z}=288.0343[\mathrm{M}]^{+}$.

\section{Data Availability}

$1 \mathrm{H}$ and 13C NMR and mass spectroscopy spectra used to support the findings of this study are available free of charge via the Internet in the Electronic Supporting Information (ESI).

\section{Disclosure}

The present research work is a part of a thesis work of a Ph.D. student.

\section{Conflicts of Interest}

The authors declare that they have no conflicts of interest.

\section{Supplementary Materials}

Figure S1: 1H NMR spectrum of product b. Figure S2: APT spectrum of product b. Figure S3: MS spectrum of product b. Figure S4: 1H NMR spectrum of product c. Figure S5: APT spectrum of product c. Figure S6: MS spectrum of product c. Figure S7: 1H NMR spectrum of product e. Figure S8: APT spectrum of product e. Figure S9: MS spectrum of product e. Figure S10: $1 \mathrm{H}$ NMR spectrum of the limonene oxide monochloride. Figure S11: 13C spectrum of the limonene oxide monochloride. Figure S12: DET 135 spectrum of the limonene oxide monochloride. Figure S13: MS spectrum of the limonene oxide monochloride. Figure S14: $1 \mathrm{H}$ NMR spectrum of the limonene oxide dichloride. Figure S15: 13C spectrum of the limonene oxide dichloride. Figure S16: DET 135 spectrum of the limonene oxide dichloride. Figure S17: MS spectrum of the limonene oxide dichloride. Figure S18: $1 \mathrm{H}$ NMR spectrum of the pulegone monochloride. Figure S19: 13C spectrum of the pulegone monochloride. Figure S20: DET 135 spectrum of the pulegone monochloride. Figure S21: MS spectrum of the pulegone monochloride. Figure S18: 1H NMR spectrum of the pulegone dichloride. Figure S19: 13C spectrum of the pulegone dichloride. Figure S20: DET 135 spectrum of the pulegone dichloride. Figure S21: MS spectrum of the pulegone dichloride. Figure S22: $1 \mathrm{H}$ NMR spectrum of the perillyl aldehyde monochloride. Figure S23: APT spectrum of the perillyl aldehyde monochloride. Figure S24: DET 135 spectrum of the perillyl aldehyde monochloride. Figure S25: MS spectrum of the perillyl aldehyde monochloride. Figure S26: $1 \mathrm{H}$ NMR spectrum of the perillyl aldehyde vinyl allyl chloride. Figure S27: APT spectrum of the perillyl aldehyde vinyl allyl chloride. Figure S28: DET 135 spectrum of the perillyl aldehyde vinyl allyl chloride. Figure S29: MS spectrum of the perillyl aldehyde vinyl allyl chloride. Figure S30: $1 \mathrm{H}$ NMR 
spectrum of the limona ketone dichloride. Figure S31: 13C spectrum of the limona ketone dichloride. Figure S32: DET 135 spectrum of the limona ketone dichloride. Figure S33: MS spectrum of the limona ketone dichloride. Figure S34: $1 \mathrm{H}$ NMR spectrum of the nootkatone monochloride. Figure S35: 13C spectrum of the nootkatone monochloride. Figure S36: DET 135 spectrum of the nootkatone monochloride. Figure S37: MS spectrum of the nootkatone monochloride. Figure S38: 1H NMR spectrum of the nootkatone dichloride. Figure S39: 13C spectrum of the nootkatone dichloride. Figure S40: DET 135 spectrum of the nootkatone dichloride. Figure S41: MS spectrum of the nootkatone dichloride. (Supplementary Materials)

\section{References}

[1] B. M. Fraga, "Natural sesquiterpenoids," Natural Product Reports, vol. 19, no. 5, pp. 650-672, 2002.

[2] B. M. Fraga, "Natural sesquiterpenoids," Natural Product Reports, vol. 18, no. 6, pp. 650-673, 2001.

[3] B. M. Fraga, "Natural sesquiterpenoids," Natural Product Reports, vol. 16, no. 6, pp. 711-730, 1999.

[4] S. Bartel and F. Bohlmann, "Total synthesis of the elemanolides $( \pm)$ zempoalin A and B," Tetrahedron Letters, vol. 30, no. 6, pp. 685-688, 1989.

[5] A. F. Barrero, J. E. Oltra, and M. Álvarez, "A new strategy for the synthesis of $(+)$-vernolepin related compounds: an unusual sulfene elimination leads to the 2-oxa-cis-decalin skeleton," Tetrahedron Letters, vol. 41, no. 40, pp. 7639-7643, 2000.

[6] W. F. Erman, Chemistry of the Monoterpenes: An Encyclopedic Handbook, Marcel Dekker, New York, NY, USA, 1985.

[7] E. V. Gusevskaya, "Organometallic catalysis: some contributions to organic synthesis," Química Nova, vol. 26, no. 2, pp. 242-248, 2003.

[8] C. Botteghi, M. Marchetti, and S. Paganelli, "New opportunities in hydroformylation: selected syntheses of intermediates and fine chemicals," in Transition Metals for Organic Synthesis, pp. 23-48, Wiley-VCH Verlag GmbH, Weinheim, Germany, 2008.

[9] T. J. Brocksom, P. R. Zanotto, and U. Brocksom, "The enantioselective syntheses of bisabolane sesquiterpenes lepistirone and cheimonophyllon E," Tetrahedron Letters, vol. 46, no. 14, pp. 2397-2398, 2005.

[10] Y. Chen, G. Zhou, L. Liu, Z. Xiong, and Y. Li, "Enantioselective total synthesis of eudesma-3,11(13)-dien-12-oic acid," Synthesis, vol. 2001, no. 9, pp. 1305-1307, 2001.

[11] M. Groesbeek and S. O. Smith, "Synthesis of 19-fluororetinal and 20-fluororetinal," The Journal of Organic Chemistry, vol. 62, no. 11, pp. 3638-3641, 1997.

[12] C. Nájera and J. M. Sansano, "2-(Chloromethyl)-3-tosylpropene: an useful reagent for the synthesis of allyl sulfones," Tetrahedron, vol. 48, no. 24, pp. 5179-5190, 1992.

[13] G. Grue-Soerensen, I. M. Nielsen, and C. K. Nielsen, "Derivatives of 2-methylenepropane-1,3-diol as new antagonists of platelet activating factor," Journal of Medicinal Chemistry, vol. 31, no. 6, pp. 1174-1178, 1988.

[14] S. El Houssame, A. A. Mekkaoui, S. Jennane et al., "Palladium(0)-catalyzed allylic substitution of optically active natural terpenic functionalized olefins," Journal of Materials and Environmental Science, vol. 8, no. S, pp. 4778-4784, 2017.

[15] S. E. Houssame, L. E. Firdoussi, S. Allaoud, A. Karim, Y. Castanet, and A. Mortreux, "Palladium-catalyzed alkoxycarbonylation of allylic natural terpenic functionalized olefins," Journal of Molecular Catalysis A: Chemical, vol. 168, no. 1-2, pp. 15-23, 2001.

[16] G. Mignani and D. Morel, "Rhône-Poulenc Santé," European Patent, 1987.

[17] G. Mignani, F. Grass, M. Aufrand, and D. Morel, "Synthesis of new unsaturated esters, catalysed by palladium-phosphine complexes," Tetrahedron Letters, vol. 30, no. 18, pp. 2383-2386, 1989.

[18] G. Mignani, C. Chevalier, F. Grass, G. Allmang, and D. Morel, "Synthesis of new unsaturated enynes, catalysed by copper (I) complexes," Tetrahedron Letters, vol. 31, no. 36, pp. 5161-5164, 1990.

[19] H. Jo, J. Lee, H. Kim, S. Kim, and D. Kim, "Efficient construction of bicyclic systems by an internal $\mathrm{SN} 2{ }^{\prime}$ enolate alkylation/ring-closing metathesis (RCM) strategy: a concise synthesis of the trans-hydrindane nucleus," Tetrahedron Letters, vol. 44, no. 37, pp. 7043-7044, 2003.

[20] T. Takahashi, A. Furutani, and S. Seko, "Process for the preparation of halogenated compounds," PCT "International" Patent Application WO200061530-A, 2000.

[21] P. V. S. N. Vani, A. S. Chida, R. Srinivasan, M. Chandrasekharam, and A. K. Singh, "Synthesis of $\beta$-IONONE\#," Synthetic Communications, vol. 31, no. 2, pp. 219-224, 2001.

[22] L.-H. Xu and E. P. Kündig, "Efficient synthesis of methyl 2(tert-Butyl)acrylate and analogous esters," Helvetica Chimica Acta, vol. 77, no. 6, pp. 1480-1484, 1994.

[23] M. Labrouillère, C. Le Roux, H. Gaspard-Iloughmane, and J. Dubac, "Bismuth (III) chloride-catalyzed chlorination of alcohols by Chlorosilanes1," Synlett, vol. 1994, no. 9, pp. 723-724, 1994.

[24] M. Tandiary, Y. Masui, and M. Onaka, "Chlorination of benzylic and allylic alcohols with trimethylsilyl chloride enhanced by natural sodium montmorillonite," Synlett, vol. 25, pp. 2639-2643, 2014.

[25] E. W. Collington and A. I. Meyers, "Facile and specific conversion of allylic alcohols to allylic chlorides without rearrangement," The Journal of Organic Chemistry, vol. 36, no. 20, pp. 3044-3045, 1971.

[26] A. Vázquez-Romero, A. B. Gómez, and B. Martín-Matute, "Acid- and iridium-catalyzed tandem 1,3-transposition/3,1hydrogen shift/chlorination of allylic alcohols," ACS Catalysis, vol. 5, no. 2, pp. 708-714, 2015.

[27] N. Ahlsten, A. Bermejo Gómez, and B. Martín-Matute, "Iridium-catalyzed 1,3-hydrogen shift/chlorination of allylic alcohols," Angewandte Chemie International Edition, vol. 52, no. 24, pp. 6273-6276, 2013.

[28] P. C. Ravikumar, L. Yao, and F. F. Fleming, "Allylic and allenic halide synthesis via $\mathrm{NbCl} 5$ - and $\mathrm{NbBr} 5$-mediated alkoxide rearrangements," The Journal of Organic Chemistry, vol. 74, no. 19, pp. 7294-7299, 2009.

[29] S. Torii, K. Uneyama, T. Nakai, and T. Yasuda, "An electrochemical chlorinative ene-type reaction of isoprenoids," Tetrahedron Letters, vol. 22, no. 24, pp. 2291-2294, 1981.

[30] S. Torii, H. Tanaka, N. Saitoh, T. Siroi, M. Sasaoka, and J. Nokami, "Chemoselective electrolytic chlorination of methyl group of 3-methyl-3-butenoate moiety of thiazolineazetidinone homologues," Tetrahedron Letters, vol. 22, no. 33, pp. 3193-3196, 1981.

[31] T. Hori and K. B. Sharpless, "Conversion of allylic phenylselenides to the rearranged allylic chlorides by $\mathrm{N}$-chlorosuccinimide. Mechanism of selenium-catalyzed allylic 
chlorination of .beta.-pinene," The Journal of Organic Chemistry, vol. 44, no. 23, pp. 4208-4210, 1979.

[32] T. Hori and K. B. Sharpless, "Selenium-catalyzed nonradical chlorination of olefins with N-chlorosuccinimide," The Journal of Organic Chemistry, vol. 44, no. 23, pp. 4204-4208, 1979.

[33] J. A. Tunge and S. R. Mellegaard, "Selective selenocatalytic allylic chlorination," Organic Letters, vol. 6, no. 8, pp. 1205-1207, 2004.

[34] A. F. Barrero, J. F. Quílez del Moral, M. M. Herrador et al., "Solid-phase selenium-catalyzed selective allylic chlorination of polyprenoids: facile syntheses of biologically active terpenoids," The Journal of Organic Chemistry, vol. 71, no. 15, pp. 5811-5814, 2006.

[35] B. Boualy, S. El Houssame, L. Sancineto et al., "A mild and efficient method for the synthesis of a new optically active diallyl selenide and its catalytic activity in the allylic chlorination of natural terpenes," New Journal of Chemistry, vol. 40, no. 4, pp. 3395-3399, 2016.

[36] M. Yamanaka, M. Arisawa, A. Nishida, and M. Nakagawa, "An intriguing effect of $\mathrm{Yb}(\mathrm{OTf}) 3-\mathrm{TMSCl}$ in the halogenation of 1,1-disubstituted alkenes by NXS: selective synthesis of allyl halides," Tetrahedron Letters, vol. 43, no. 13, pp. 2403-2406, 2002.

[37] R. C. Samanta and H. Yamamoto, "Selective halogenation using an aniline catalyst," Chemistry-A European Journal, vol. 21, no. 34, pp. 11976-11979, 2015.

[38] F. J. Moreno-Dorado, F. M. Guerra, F. L. Manzano, F. J. Aladro, Z. D. Jorge, and G. M. Massanet, "CeCl3/NaClO: a safe and efficient reagent for the allylic chlorination of terminal olefins," Tetrahedron Letters, vol. 44, no. 35, pp. 6691-6693, 2003.

[39] S. G. Hegde, M. K. Vogel, J. Saddler et al., "The reaction of hypochlorous acid with olefins. A convenient synthesis of allylic chlorides," Tetrahedron Letters, vol. 21, no. 5, pp. 441-444, 1980.

[40] S. G. Hegde and J. Wolinsky, "Synthesis with hypochlorous acid-functionalization of an isopropenyl group. Syntheses of (+)-bilobanone and the juvabiones," The Journal of Organic Chemistry, vol. 47, no. 16, pp. 3148-3150, 1982.

[41] Z. Xiong, J. Yang, and Y. Li, “An efficient asymmetric route to eudesmane acids. Total synthesis of (+)-12-hydroxy$\alpha$-cyperone, (+)-12-oxo- $\alpha$-cyperone and (+)-3-oxoeudesma4,11(13)-dien-12-oic acid," Tetrahedron Asymmetry, vol. 7, pp. 2607-2612, 1996.

[42] M. P. VanBrunt, R. O. Ambenge, and S. M. Weinreb, "A mild, convenient, and inexpensive procedure for conversion of vinyl halides to $\alpha$-haloketones," The Journal of Organic Chemistry, vol. 68, no. 8, pp. 3323-3326, 2003.

[43] D. S. Pisoni, D. Gamba, C. V. Fonseca et al., "InCl3NaClO: a reagent for allylic chlorination of terminal olefins," Journal of the Brazilian Chemical Society, vol. 17, pp. 321-327, 2006.

[44] B. Boualy, L. E. Firdoussi, M. A. Ali, and A. Karim, "Allylic chlorination of terpenic olefins using a combination of $\mathrm{MoCl} 5$ and NaOCl," Journal of the Brazilian Chemical Society, vol. 22, no. 7, pp. 1259-1262, 2011.

[45] A. Aberkouks, A. A. Mekkaoui, B. Boualy, S. EL Houssame, M. Ait Ali, and L. El Firdoussi, "Co-Ag supported ZnO: an efficient and recyclable heterogeneous catalyst for the oxidation of natural terpenes," Materials Today: Proceedings, vol. 13, pp. 453-457, 2019.

[46] A. Aberkouks, A. A. Mekkaoui, M. Ait Ali, L. El Firdoussi, and S. El Houssame, "Selective allylic oxidation of terpenic olefins using Co-Ag supported on $\mathrm{SiO}_{2}$ as a novel, efficient, and recyclable catalyst," Journal of Chemistry, vol. 2020, Article ID 1241952, 11 pages, 2020.

[47] A. A. Mekkaoui, A. Aberkouks, L. Fkhar, M. Ait Ali, L. El Firdoussi, and S. El Houssame, "Novel palladium nanoparticles supported on mesoporous natural phosphate: catalytic ability for the preparation of aromatic hydrocarbons from natural terpenes," Applied Organometallic Chemistry, vol. 34, no. 11, pp. e5917-11, 2020.

[48] M. E. Furrow and A. G. Myers, "Practical procedures for the preparation of N-tert-Butyldimethylsilylhydrazones and their use in modified Wolff-Kishner reductions and in the synthesis of vinyl halides andgem-dihalides," Journal of the American Chemical Society, vol. 126, no. 17, pp. 5436-5445, 2004.

[49] K. Kamei, N. Maeda, and T. Tatsuoka, "A practical synthetic method for vinyl chlorides and vinyl bromides from ketones via the corresponding vinyl phosphate intermediates," Tetrahedron Letters, vol. 46, no. 2, pp. 229-232, 2005. 